\title{
A escola e as perspectivas educacionais de jovens em situação de risco
}

\section{Perspectivas educacionais de jovens}

\author{
Deise Matos do Amparo \\ Afonso Celso Tanus Galvão \\ Carmen Cardenas \\ Sílvia Helena Koller
}

\begin{abstract}
Resumo
Este estudo visou identificar a percepção de jovens em situação de risco psicossocial sobre a realização e aspirações escolares e a rede de apoio social relacionadas ao contexto de ensino-aprendizagem. Investigou proteção e vulnerabilidade no contexto escolar, com base na Abordagem Ecológica do Desenvolvimento e a Psicologia Positiva. 852 jovens, de ambos os sexos, do ensino médio público de regiões administrativas do Distrito Federal responderam a um questionário sobre relações com professores e amigos, qualidade e importância da escola, reprovação e fracasso escolar e rede de apoio social e afetiva. Os resultados revelaram que a escola se constitui numa importante rede de proteção, com a qual os jovens apresentam, em geral, atitudes positivas de confiança e interesse. A continuidade da formação é valorizada e a escola está incluída em projetos futuros destes jovens. Os amigos, professores e pais representam importantes fatores de proteção no contexto escolar.
\end{abstract}

Palavras-chave: aprendizagem; escola; atitudes.

\section{The school and the educational perspectives of at risk situations}

\begin{abstract}
This study aimed at identifying youths in a situation of psychosocial risk, their school achievement and aspiration, and their social support network related to their teaching-learning context. It investigated protection and vulnerability in the school context based on positive psychology and the ecological approach to development. Participants were 852 males and females secondary state school students, from administrative regions of the Federal District Brazil. They answered to a lengthy questionnaire about their relationship with colleagues and teachers, school quality and importance, school failure and their social-affective network. Results show the school as an important net of protection to which participants associate attitudes of confidence and interest. They value the continuity of their education and the school is included their projects for the future. In the school context, friends, teachers and parents represent important protection factors.
\end{abstract}

Keywords: learning; school; attitudes.

\section{La escuela y las perspectivas educacionales de jóvenes en situación de riesgo}

\section{Resumen}

Este estudio tuvo como objetivo identificar la percepción de jóvenes en situación de riesgo psico-social sobre la realización y aspiraciones escolares y la red de apoyo social relacionada al contexto enseñanza-aprendizaje. Investigó protección y vulnerabilidad en el contexto escolar, con base en la Línea Ecológica del Desarrollo y la Psicología Positiva. 852 jóvenes de ambos sexos, de la enseñanza secundaria pública de regiones administrativas del Distrito Federal respondieron a un cuestionario sobre relaciones con profesores y amigos, calidad e importancia de la escuela, reprobación y fracaso escolar y red de apoyo social y afectivo. Los resultados revelaron que la escuela se constituye como una importante red de protección con la cual los jóvenes presentan, generalmente, actitudes positivas de confianza e interés. La continuidad de la formación es valorizada y la escuela está incluida en proyectos futuros de esos jóvenes. Los amigos, profesores y padres representan factores importantes de protección en el contexto escolar.

Palabras clave: aprendizaje; escuela; actitudes. 


\section{Introdução}

\section{Juventude: risco e proteção}

A educação do importante contingente populacional formado pela juventude brasileira é, sem dúvida, um dos maiores desafios que se colocam para as políticas sociais neste início de milênio. A síntese de indicadores sociais da Pesquisa Nacional por Amostra de Domicílios (PNAD, Instituto Brasileiro de Geografia e Estatística, 2005) mostrou que 14,9 milhões de pessoas com 15 anos ou mais de idade, ou seja, $11 \%$ da população brasileira não sabem ler nem escrever.

A carência do acesso ao ensino médio e à educação superior é ainda maior, especialmente, se o(a) jovem fizer parte da camada pobre da população, conforme aponta o Relatório de Desenvolvimento Juvenil 2006, da Organização dos Estados Ibero-Americanos para Educação, Ciência e Cultura (OEI), divulgado em 2006. Os índices utilizados baseiam-se em critérios e dimensões semelhantes aos propostos pelo Índice de Desenvolvimento Humano (IDH), do Programa das Nações Unidas para o Desenvolvimento (PNUD), adaptando-os de modo a contemplar questões e situações específicas dos jovens na faixa etária de 15 a 24 anos. Este dado também foi discutido por Sposito e Corrochano (2005), que apontam os jovens como os mais prejudicados por processos de exclusão, mesmo dentro de políticas públicas geradas para eles. Além de o impacto destas, muitas vezes, ser desconhecido, a participação em programas destinados a jovens de baixa renda exige, geralmente, matrícula na escola. Tal matrícula é feita, às vezes, só formalmente, pois a história de relacionamento do jovem com a instituição escolar já é de fracasso. Fracasso este que é mais da própria escola do que dele mesmo.

Um estudo de Waiselfisz (2006), feito com base no PNAD de 2003, confirma que o quadro já era bastante preocupante em anos anteriores, uma vez que $51 \%$ ou 17,8 milhões de jovens nesta faixa etária já estavam fora da escola ou da universidade e outros $19,8 \%$ (7 milhões de jovens), não trabalhavam nem estudavam.

A visão das estatísticas é avassaladora e a psicologia precisa, portanto, buscar compreender o lugar da escola na vida dos jovens, resgatando o significado da mesma. Portanto, este estudo focaliza aspectos apresentados pelos próprios jovens em situação de risco psicossocial, buscando identificar o papel da escola na sua formação. São abordados aspectos relativos à proteção e à vulnerabilidade por meio do levantamento de indicadores relativos à escolaridade (pessoal e dos pais), percepção da qualidade e importância da escola, histórico de reprovação e dificuldade, rede de amigos neste contexto, relação com professores e rede de apoio.

$\mathrm{O}$ conceito de juventude tem sido definido com variações na literatura atual. Para Waiselfisz (2006), a fase da juventude pode ser apontada como um período de transição que se inicia na adolescência e segue até a idade adulta. Mas Sposito (2000) contesta uma definição fechada como esta, explicando que é difícil definir um grupo heterogêneo como se coubesse em uma única categoria. Neste estudo será utilizada a conceitualização de Waiselfisz, com base na demarcação do ciclo vital do grupo estudado, sem, no entanto, perder de vista a possibilidade de 
contrastes entre os jovens investigados e a especificidade da caracterização da amostra. Esta tem predomínio de $68,5 \%$ dos jovens tudo na faixa etária de 15 a 17 anos.

A idéia principal, no entanto, é considerar que jovens são pessoas em desenvolvimento que, como propõe Bronfenbrenner (2005), experienciam mudanças e constâncias (estabilidade, continuidade) ao longo de seus ciclos vitais, tanto individualmente quanto como grupo (cultural, geracional e historicamente). No caso de jovens em situação de risco social e pessoal, os efeitos cumulativos (que envolvem mudanças freqüentes) ou o simples fato de haver risco (estabilidade) pode influenciar no desenvolvimento e em seu ajustamento psicológico.

Desenvolvimento em situação de risco envolve obstáculos individuais ou ambientais que aumentariam a vulnerabilidade dos jovens para resultados negativos no seu desenvolvimento. Tradicionalmente, os fatores de risco eram definidos por termos estáticos como estressores (pobreza, maus-tratos), porém hoje, atenta-se para a importância de analisar os fatores de risco enquanto processo envolvendo a quantidade de exposição aos fatores de risco, o tempo, o momento e o contexto (Engle, Castle, \& Menon, 1996). Nesse sentido, a existência de um único risco isolado, que seja enfrentado gerando adaptação ou superação, não permite identificar um(a) jovem como vulnerável. O processo de superação ao risco tem sido amplamente estudado, buscando identificar aspectos protetivos, que gerem políticas públicas e sociais extensivas a outros jovens (Dell'Aglio, Koller, \& Yunes, 2006).

Um risco pode, no entanto, ser físico, social ou psicológico, originado de causas internas e externas que causam danos importantes, se não forem identificados e combatidos. As causas externas, em geral, relacionam-se às condições adversas do ambiente (pobreza, violência, desemprego). As causas internas aparecem em jovens que podem, por exemplo, sofrer de depressão, apresentar baixa auto-eficácia e/ou problemas de aprendizagem, entre outros. A interação de causas externas e internas tem tido importante relação com comportamentos de risco expressos pelos próprios jovens, que se reflete em atitudes que aumentam a incidência de condições adversas, afetando o desenvolvimento e a saúde do jovem. Uso de drogas, comportamento sexual promíscuo, relações sexuais desprotegidas, carência de modelos apropriados, socialização inadequada podem ser considerados comportamentos de risco, dos quais os jovens são os próprios protagonistas. O espectro é bastante amplo e não se situa exclusivamente nas classes sociais mais pobres, muito embora a miséria seja um fator de risco universal (Zimmerman \& Arunkumar, 1994).

A prevalência de fatores de risco na adolescência e na juventude têm configurado esses momentos do desenvolvimento como de vulnerabilidade e fragilidade. Tal quadro demanda atenção e cuidado em relação aos fatores de risco e proteção. A prevenção pelo auto-cuidado, preservação da saúde, combate à violência, ao uso de drogas, aos maus tratos; em relação a si, na família e no contexto social mais amplo têm sido demarcadores de resiliência. Nesse processo saudável está inserido o contexto da escola, que comparece com lugar de destaque enquanto fator de formação e de socialização e como importante fonte de apoio social e afetivo. 
Professores e colegas têm sido identificados como importantes recursos emocionais no contexto escolar favorecendo o desenvolvimento de processos proximais, que são definidos pela interação recíproca, progressivamente mais complexa de um ser humano ativo, biopsicologicamente em evolução, com as pessoas, objetos e símbolos do seu ambiente imediato (Leite \& Tagliaferro, 2005). Bronfenbrenner e Morris (1998) definiram processo proximal como o motor do desenvolvimento. Outros apoios do ambiente externo têm sido oferecidos por pessoas significativas da igreja, de grupos de ajuda, que promovem bons relacionamentos como amigos, modelos e referência segura à pessoa em desenvolvimento (Branden, 1998; Garmezy \& Masten, 1994). Outro aspecto que é considerado um fator de proteção é a coesão familiar e ausência de negligência dentro do contexto no qual residem os(as) jovens. A possibilidade de administrar conflitos, com a presença de pelo menos um adulto com grande interesse por ele(a), a presença de laços afetivos, estabilidade, respeito mútuo, apoio/suporte no sistema familiar e/ou em outros contextos que ofereçam suporte emocional em momentos de estresse, possibilita o que Morais e Koller (2004) chamam de coesão ecológica, que se aplica a todos e quaisquer contextos de desenvolvimento. Características individuais, tais como auto-estima positiva, autocontrole, autonomia, perfil de temperamento afetuoso, flexível e inteligência são aspectos considerados fatores de proteção. Uma pessoa que apresenta características saudáveis poderá ter melhores condições de enfrentar os riscos como desafios e não como impossibilidades (Rutter, 1987, 1993).
A presença de um fator de proteção pode determinar o surgimento de outros fatores em algum outro momento. Estes fatores amenizam o impacto dos riscos e proporcionam alternativas para resolução dos problemas. Portanto, compreender de que forma esses mediadores agem para atenuar os efeitos negativos do risco é tarefa tão complexa quanto determinar o que é fator de adversidade para cada ser humano (Pesce, Assis, Santos \& Oliveira, 2005).

Quatro principais funções são atribuídas aos processos de proteção: reduzir o impacto dos riscos, fato que altera a exposição da pessoa à situação adversa; significa oferecer apoio afetivo por parte dos significantes mais próximos, isto é, familiares e, em ambiente mais amplo, professores na escola supervisão e calor empático; reduzir as reações negativas em cadeia que exponham o indivíduo à situação de risco; sugere-se que o indivíduo deva mobilizar seus recursos pessoais, tais como autoconhecimento e autoconfiança; estabelecer e manter a auto-estima e auto-eficácia, por meio do estabelecimento de relações de apego seguras e o cumprimento de tarefas com sucesso; e, criar soluções e oportunidades para reverter os efeitos do estresse gerado (Rutter, 1987). Em suma, fatores que auxiliam o ser humano a lidar e superar situações impostas ao longo de seu desenvolvimento são apontados em abundância na literatura.

A análise do contexto escolar e seu papel no desenvolvimento social e afetivo das pessoas tem sido um tema muito polêmico, como apontam Lisboa e Koller (2004). A escola tem sido amplamente questionada sob o ponto de vista do risco e da proteção, não podendo ser considerada 
apenas como um espaço para aprendizagem formal ou desenvolvimento da cognição, mas como uma oportunidade fundamental para a socialização de jovens na cultura ocidental moderna. O contexto escolar extrapola a delimitação do ambiente físico, agrupando o ambiente social (professores, colegas) e de aprendizagem (trocas, conteúdos, materiais, informações). Sua função deve ser reconhecida como maior do que lidar com a cognição, acrescentando o afeto e as mais variadas formas de expressão do jovem por meio da ação (Lisboa \& Koller. 2004). A escola promoverá resiliência se apresentar experiências como desafios e não como ameaças, construindo interações de qualidade com estabilidade e coesão, compondo uma rede de apoio com o ambiente, que demonstre reconhecimento, aceitação e ofereça limites (Pinheiro, 2004). Ou seja, o que faz da escola uma instituição que se firma como uma instituição protetora encontra-se relacionado com o parâmetro de a escola ser constituída de sujeitos e são eles, em suas interações próximas e simbólicas, que constroem e consolidam esta instituição como uma instituição protetiva.

A Abordagem Ecológica do Desenvolvimento Humano (AEDH) e a psicologia positiva são os paradigmas que embasam teórica e metodologicamente esta investigação. Foram utilizadas para a confecção do questionário e para a análise das perspectivas educacionais dos adolescentes.

\section{A abordagem ecológica do desenvolvimento e a psicologia positiva}

A ecologia do desenvolvimento humano considera que comportamentos devem ser examinados como um conjunto de funções das características da pessoa e do ambiente (Bronfenbrenner, 1996, 1989). Nessa perspectiva, o desenvolvimento é contextual e se constitui a partir de processos por meio dos quais as particularidades da pessoa e do ambiente interagem produzindo constância e mudança nas características pessoais no decorrer da vida (Bronfenbrenner, 1989), por meio de quatro níveis dinâmicos, interrelacionados, que interagem simultaneamente: o processo, a pessoa, o contexto e o tempo. Portanto, ao serem analisados os fatores de risco e proteção esses aspectos estão implicados de forma dinâmica e interrelacionada.

O primeiro componente do modelo é o processo, que é o modo de relação entre as características da pessoa e o ambiente. Atualmente tem sido dada uma atenção maior aos processos de desenvolvimento individuais, ou seja, às diferentes formas de interação das pessoas não são mais tratadas como função do ambiente, mas como uma função do processo que é definido em termos de relação entre ambiente e as características da pessoa em desenvolvimento (Bronfenbrenner, 1996).

O segundo componente do modelo é a pessoa e nele estão envolvidas as características determinadas biopsicologicamente e as características construídas na interação com o ambiente. Bronfenbrenner e Morris (1998) distinguem três grupos de características pessoais atuantes no desenvolvimento que podem influenciar processos proximais, quais sejam: características de disposição (generativas e inibidoras), de recurso e de demanda. As características de disposição generativas envolvem orientações ativas, como curiosidade, tendência para engajar-se em 
atividades individuais ou com terceiros, respostas a iniciativas de outros e auto-eficácia. As características inibidoras referem-se às dificuldades da pessoa em manter o controle sobre suas emoções e comportamento, incluem características como: impulsividade, apatia, desatenção, irresponsabilidade, insegurança e timidez excessiva. Os recursos bioecológicos não envolvem disposição seletiva para ação, mas se constituem em condições que limitam ou inibem a integridade funcional do organismo ou capacidades e habilidades psicológicas que influenciam a pessoa para se engajar em processos proximais. As características de demanda constituem atributos pessoais capazes de solicitarem ou impedirem reações do ambiente social favorecendo ou inibindo os processos proximais no desenvolvimento psicológico.

O contexto é o terceiro componente e abrange a interação de quatro níveis ambientais: microssistema, mesossistema, exossistema e macrossistema. O microssistema é definido como um padrão de atividade, papéis e relações interpessoais que a pessoa experimenta ao longo do seu desenvolvimento nos ambientes dos quais faz parte e entra em interação face a face; é nesse contexto que operam os processos proximais, produzindo e sustentando o desenvolvimento. As interações nesse nível ocorrem com os aspectos físicos, sociais e simbólicos do ambiente e são permeados pelas características das pessoas envolvidas. O mesosistema consiste no conjunto dos microssistemas que uma pessoa freqüenta e das inter-relações que são estabelecidas entre eles. Os processos que operam nos diversos ambientes nos quais a pessoa está incluída são interdependentes e se influenciam mutuamente. Por exemplo, o ambiente escolar sofre influência de outros ambientes, como a família ou o trabalho. O exosistema é o espaço que a pessoa não freqüenta ativamente, mas tem uma influência indireta na dinâmica de suas interações: grupos que tomam decisões sobre políticas públicas, rede de apoio social e comunitária, dentre outros. $\mathrm{O}$ macrossistema refere-se ao padrão global de ideologias crenças, valores, religião, fatores que estão presentes no cotidiano e que influenciam o desenvolvimento do indivíduo (Bronfenbrenner, 1996; Bronfenbrenner \& Morris, 1998).

Por último, o desenvolvimento na abordagem ecológica considera as mudanças e as continuidades que ocorrem ao longo do ciclo de vida e são analisadas pelo Tempo. A temporalidade que acompanha o ciclo de vida das pessoas permite realizar uma análise da influência das mudanças no desenvolvimento, essas mudanças não são apenas produtos, mas também produtoras de modificações históricas (Bronfenbrenner, 1986; Bronfenbrenner \& Morris, 1998).

Associada ao modelo teórico-metodológico da AEDH a proposta teórica da Psicologia Positiva valoriza a saúde, os fatores e processos que promovem o desenvolvimento psicológico humano. Trata-se de um modelo que enfatiza uma visão mais favorável, aberta e apreciativa dos potenciais, das motivações e das capacidades humanas. É um movimento de investigação de aspectos potencialmente saudáveis dos seres humanos que enfatiza um conjunto de condições apresentadas pelo indivíduo e lhe permite a adaptação ao meio social (Seligman \& Csikszentmihalyi, 2000; Yunes, 2003). 
De acordo com essa visão, o conhecimento das forças e virtudes poderia propiciar o "florescimento" (flourishing) das pessoas, comunidades e instituições. Florescimento tem sido um termo bastante utilizado na Psicologia Positiva, sendo definido por Keyes e Haidt (2003), como uma condição que permite o desenvolvimento pleno, saudável e positivo dos aspectos psicológicos, biológicos e sociais dos seres humanos. Segundo Seligman (2002), a Psicologia deveria possibilitar muito mais do que apenas reparar o que está errado, devendo identificar e fortalecer o que está bom.

Assim, utilizando-se dessas perspectivas teóricas, esta investigação focaliza a percepção de adolescentes em situação de risco sobre a escola que freqüentam e se esta se constitui como fator de vulnerabilidade ou proteção. Essa população é considerada de risco, basicamente pela sua condição de pobreza e empobrecimento e inserção em contextos precários em habitação, sanitarismo, com índices altos de analfabetismo e criminalidade. Analisam-se os mecanismos de proteção que os jovens conferem à escola e os possibilita lidarem com as situações desfavoráveis ao seu desenvolvimento.

\section{Método}

\section{Participantes}

Os participantes da pesquisa compõem um grupo de 852 indivíduos jovens, cursando o ensino médio em escolas públicas das seguintes regiões administrativas do Distrito Federal: Planaltina, Brazlândia, Paranoá e Samambaia, com idade entre
13 e 27 anos, sendo que 68,5\% da amostra concentra-se a faixa etária de 15 a 17 anos (média de 16 anos, com desvio padrão de 1,58\%). No que diz respeito à diferença de sexos, $57,4 \%$ dos participantes são do sexo feminino, $41,5 \%$ do sexo masculino e $1,1 \%$ não se identificou. Quanto à renda salarial familiar mensal, $35 \%$ dos participantes têm rendimentos entre um e dois salários mínimos; $22 \%$ entre mais de dois a três salários mínimos; enquanto que $18,7 \%$ relatam renda superior a três salários mensais. Metade dos participantes $(52,4 \%)$ tem pais que são migrantes do interior de outros estados do Brasil. As variáveis em questão foram apresentadas apenas para caracterizar os participantes do estudo e oferecer um perfil geral da população que foi investigada. $\mathrm{O}$ cruzamento desses dados com outras variáveis serão objeto de análises mais extensivas em futuros trabalhos.

\section{Instrumento e procedimentos}

Foi utilizado um questionário para levantamento de fatores de risco e proteção, produzido para o estudo "Juventude Brasileira" (Koller, CerqueiraSantos, Morais, \& Ribeiro, 2005). O instrumento consta de 109 questões de múltipla escolha e investiga aspectos sobre a caracterização bio-sóciodemográfica dos participantes, assim como sobre as temáticas de educação, saúde (incluindo drogas e sexualidade), trabalho, violência, lazer, religiosidade, rede de apoio social, humor, autoestima e auto-eficácia. $\mathrm{O}$ instrumento foi respondido coletivamente, em pequenos grupos nas salas de aula, e o tempo de preenchimento foi, em média, uma hora e meia. Para este estudo foram utilizados os dados sobre educação/escolarização. 
A seleção da região para coleta dos dados foi realizada considerando as áreas do Distrito Federal com Índices de Desenvolvimento Humano mais baixos. Além deste dado, a renda familiar baixa, o índice de analfabetismo e a precariedade das condições de moradia foram também considerados. Para a escolha das escolas, utilizaram-se os seguintes critérios: localização (áreas com indicadores aparentes de pobreza, tais como concentração de barracos, saneamento básico inadequado), idade (de 13 a 27 anos) e nível sócioeconômico (baixo) como características da clientela atendida. Para coleta de dados, em um primeiro contato, os (as) pesquisadores (as) visitaram as escolas e apresentaram informações sobre o projeto, visando à inserção na escola de forma participativa e integrada. Todos participantes foram voluntários. Os participantes e responsáveis consentiram com a realização do estudo, tiveram esclarecimentos sobre os objetivos e assinaram o Termo de Consentimento Livre e Esclarecido. Em seguida, os questionários foram aplicados coletivamente em pequenos grupos e respondidos individualmente pelos participantes. A pesquisa foi encaminhada ao comitê de ética da Universidade Federal do Rio Grande do Sul, tendo sua aprovação sob o Protocolo n. 2005/466.

\section{Resultados}

\section{Perspectivas educacionais dos jovens}

Neste trabalho, foram explorados indicadores relacionados à vida escolar, buscando identificar a visão dos jovens em situação de risco psicossocial sobre o papel da escola na sua formação, e investigar aspectos relativos à proteção e vulnerabilidade dos participantes em relação a esse contexto. Os indicadores analisados incluem aspectos como freqüência, expulsão e reprovação, perspectivas sobre a qualidade da escola e de sua importância na vida dos participantes, tanto no que diz respeito ao presente, quanto sobre as perspectivas futuras. Além disso, foi explorado também o tipo de apoio que esses jovens recebem do corpo docente da escola e dos colegas, incluindo a avaliação que os mesmos fazem de seu futuro enquanto estudantes.

\section{Freqüiência, expulsão, reprovação}

A maioria dos jovens participantes $(95,4 \%)$ freqüenta a escola diariamente, sendo que apenas $6 \%$ relatam dificuldades para com a frequiência diária. Quanto a problemas na escola graves o suficiente para levar a expulsões, estes parecem bastante raros, pois apenas $1,9 \%$ dos participantes declararam terem sido expulsos da escola. Em contraste, o percentual de estudantes que já foram reprovados é expressivo (43,3\%). Destes, a maior parte $(57,73 \%)$ foi reprovada apenas uma vez, enquanto que $30,7 \%$ foram reprovados duas vezes. Outros $11,54 \%$ foram reprovados três vezes ou mais.

\section{Escola, educação e perspectivas futuras}

Os participantes foram solicitados a avaliar a importância dos estudos para o momento presente (Meus estudos têm grande importância para mim hoje), e para o futuro (Meus estudos têm uma importância para mim no futuro). Em uma escala de três pontos (discordo, nem discordo/nem concordo, concordo), 90,7\% afirmaram concordar que seus estudos são importantes hoje. Somente $3,1 \%$ discordaram da afirmação, enquanto $6,2 \%$ 
manifestaram um posicionamento de neutralidade (não concordam nem discordam). Com relação à potencial influência dos estudos no futuro (também em uma escala de três pontos), $94 \%$ indicam que os estudos têm importância para o futuro. A Tabela 1 oferece um detalhamento maior das respostas.

Ainda em uma escala de três pontos (discordo, nem discordo/nem concordo, concordo), os jovens indicaram se tinham desejo de fazer uma faculdade, se a sua realização pessoal envolvia cursar um curso superior, se consideravam que tinham condições de ingressar em uma faculdade e se pensavam que para alcançar seus objetivos teriam que estudar muito. A maioria dos participantes $(84,3 \%)$ revelou ter desejo de freqüentar uma universidade, sendo que para $75,4 \%$, alcançar o nível superior ocupa um lugar no contexto maior da realização pessoal, embora somente um pouco mais da metade dos participantes se considerem bons estudantes $(52,9 \%)$, tendo uma percepção positiva sobre a própria capacidade de entrar para a universidade $(57 \%)$. Ao serem perguntados sobre a possibilidade de entrar para a universidade, tendo estudado em escolas públicas, a opinião majoritária $(73,6 \%)$ dos jovens foi bastante otimista, ou seja, declararam ser possível, embora isso envolva um esforço pessoal considerável, conforme apontado por 90,4\%. Tal otimismo, no entanto, é resfriado em outro item do questionário, em que $45,6 \%$ dos participantes discordaram da afirmação de que só quem estuda em escola particular consegue entrar para a universidade $(17,5 \%$ se mantiveram neutros, enquanto que $36,9 \%$ concordaram com a afirmação). Observados em conjunto, estes dados sugerem um sentimento ambíguo: por um lado, os participantes acreditam em si mesmos, por outro, sabem que a competição com estudantes de escolas particulares pode ser complicada.

\section{Percepções sobre o contexto da escola}

Neste quesito, primeiramente se buscou explorar o sentimento geral dos participantes em relação ao ambiente escolar. Buscou-se também identificar percepções sobre a qualidade da escola e a dinâmica dos relacionamentos ali desenvolvidos entre professores, estudantes e a escola. Aqui, duas questões particularmente importantes dizem respeito ao modo como os estudantes avaliam a escola e pelas motivações que têm para permanecerem nela. Em geral, os participantes expressaram sentir-se bem quando estão na escola, demonstrando gostarem tanto da maioria dos professores quanto da maioria dos amigos ali conquistado.

Ao serem solicitados a avaliar a escola, 12,1\% dos jovens responderam que é muito boa e $37,1 \%$, que é boa. Relativamente poucos respondentes declararam considerar ruim a escola na qual estudam $(8,9 \%)$, ou muito ruim $(3,8 \%)$. Deve, no entanto, ser enfatizado que $37,7 \%$ consideram a qualidade apenas razoável. Ao serem solicitados a avaliar a sentença 'quero continuar meus estudos na mesma escola', 58,3\% concordaram, 21,4\% discordaram e $20,3 \%$ apresentaram posicionamento neutro. Além disso, a maioria dos respondentes declarou gostar de ir para a escola $(65,7 \%)$, gostar da maioria dos professores $(60,4 \%)$ e gostar da maioria dos amigos que têm na escola $(77,9 \%)$, como indica a Tabela 2. Nota-se que destas três dimensões relacionadas ao posicionamento afetivo dos estudantes, a que se refere aos professores é menos expressiva. Em outras palavras, há uma 
Tabela 1. Escola, educação e perspectivas futuras dos jovens participantes.

\begin{tabular}{lrrrr}
\hline Item & & Concordo & $\begin{array}{c}\text { Nem Discordo } \\
\text { Nem Concordo }\end{array}$ & Discordo \\
\hline Meus estudos têm grande importância & $\%$ & 90,7 & 6,2 & 3,1 \\
para mim hoje & $n$ & 752,0 & 51,0 & 26,0 \\
\hline Meus estudos têm uma importância & $\%$ & 94,0 & 3,7 & 2,3 \\
para mim no futuro & $n$ & 779,0 & 31,0 & 19,0 \\
\hline Tenho muito desejo de fazer uma & $\%$ & 84,3 & 11,3 & 4,4 \\
faculdade & $n$ & 689,0 & 92,0 & 36,0 \\
\hline Minha realização pessoal envolve & $\%$ & 75,4 & 19,2 & 5,3 \\
fazer uma faculdade & $n$ & 614,0 & 156,0 & 43,0 \\
\hline & $\%$ & 52,9 & 38,7 & 8,4 \\
Considero-me bom estudante & $n$ & 434,0 & 317,0 & 69,0 \\
\hline Sei que tenho condições de fazer uma & $\%$ & 57,0 & 28,9 & 14,0 \\
faculdade & $n$ & 455,0 & 231,0 & 112,0 \\
\hline Só quem vai à escola particular pode & $\%$ & 9,9 & 16,5 & 73,6 \\
entrar na universidade & $n$ & 81,0 & 136,0 & 605,0 \\
\hline Para alcançar o que sonho preciso & $\%$ & 90,4 & 6,1 & 3,5 \\
estudar muito & $n$ & 750,0 & 51,0 & 29,0 \\
\hline
\end{tabular}

Tabela 2. Percepção dos jovens sobre amigos, professores e qualidade da escola.

\begin{tabular}{lrrrr}
\hline Item & & Concordo & $\begin{array}{r}\text { Nem Discordo } \\
\text { Nem Concordo }\end{array}$ & Discordo \\
\hline Quero continuar meus & $\%$ & 58,3 & 21,4 & 20,3 \\
estudos na mesma escola & $n$ & 476,0 & 166,0 & 175,0 \\
& $\%$ & 65,7 & 25 & 9,3 \\
Gosto de ir para a escola & $n$ & 546,0 & 208,0 & 77,0 \\
Gosto da maioria dos & $\%$ & 60,4 & 24,2 & 15,3 \\
professores & $n$ & 498,0 & 199,0 & 126,0 \\
Gosto da maioria dos & $\%$ & 77,9 & 15,8 & 6,3 \\
amigos que tenho na & $n$ & 642,0 & 130,0 & 52,0 \\
escola & & &
\end{tabular}


Tabela 3. Funcionamento da rede de apoio sócio-afetivo dos jovens.

\begin{tabular}{|c|c|c|c|c|}
\hline Item & & Concordo & $\begin{array}{l}\text { Nem Discordo } \\
\text { Nem Concordo }\end{array}$ & Discordo \\
\hline \multirow{2}{*}{$\begin{array}{l}\text { Meus pais ou familiares } \\
\text { incentivam muito os meus } \\
\text { estudos }\end{array}$} & $\%$ & 86,5 & 9,3 & 4,1 \\
\hline & $n$ & 714,0 & 77,0 & 34,0 \\
\hline \multirow{2}{*}{$\begin{array}{l}\text { Posso contar com alguém da } \\
\text { equipe escolar }\end{array}$} & $\%$ & 40,5 & 41,3 & 18,2 \\
\hline & $n$ & 332,0 & 338,0 & 149,0 \\
\hline \multirow{2}{*}{$\begin{array}{l}\text { Confio na maioria dos } \\
\text { professores }\end{array}$} & $\%$ & 37,7 & 39,4 & 23,0 \\
\hline & $n$ & 305,0 & 319,0 & 186,0 \\
\hline \multirow{2}{*}{$\begin{array}{l}\text { Se precisar, sei que posso } \\
\text { contar com a ajuda dos } \\
\text { amigos }\end{array}$} & $\%$ & 50,9 & 36,5 & 12,7 \\
\hline & $n$ & 417,0 & 299,0 & 104,0 \\
\hline \multirow{2}{*}{$\begin{array}{l}\text { Confio nos amigos da } \\
\text { escola }\end{array}$} & $\%$ & 39,2 & 41,4 & 19,4 \\
\hline & $n$ & 319,0 & 337,0 & 158,0 \\
\hline
\end{tabular}

tendência dos respondentes de gostarem mais de freqüentar a escola, e dos amigos que têm lá, do que dos professores.

\section{Rede de apoio sócio-afetivo dos jovens}

Um aspecto muito importante do sucesso acadêmico diz respeito à rede social e afetiva de apoio. As relações de amizade e nos grupos, que fornecem aos estudantes a percepção de pertencimento e de ter alguém com quem possam contar os empoderam para desenvolver tanto os aspectos mais relacionados a processos de aprendizagem, quanto para se manterem motivados para o estudo. As relações estabelecidas no contexto escolar têm sido descritas como importantes atrativos dos estudantes para permanência e freqüência à escola.

Alguns itens do questionário indagaram sobre a percepção de apoio recebido pelos participantes a partir de pessoas significativas no contexto da escola, tais como professores, amigos, equipe escolar e família (ver Tabela 3). Os participantes são apoiados pelo núcleo familiar, pois $86,5 \%$ deles declararam que os familiares incentivam muito os seus estudos. No que diz respeito aos atores escolares, no entanto, as respostas não foram tão positivas. Considerando a importância dos professores na mediação da aprendizagem e seu significado geral no contexto da escola, parece preocupante que, relativamente, poucos respondentes declararam poder contar com $(40,5 \%)$ ou confiar $(37,7 \%)$ na maioria dos professores. Houve uma quantidade correspondente de estudantes que se posicionaram de modo neutro quanto a poder contar $(41,3 \%)$ e confiar $(39,4 \%)$. Preocupa, no entanto, o percentual relativamente alto de respondentes que informa que não pode nem contar com a ajuda $(18,2 \%)$ e nem confiar $(23 \%)$ nos professores da escola que freqüentam. Em contraste, há $50,9 \%$ de respondentes que indicam 
poder contar com a ajuda dos amigos, embora somente $39,2 \%$ informem que podem confiar neles.

Em todo caso, o posicionamento neutro (nem concorda/nem discorda) em relação a confiar $(41,4 \%)$ e poder contar com a ajuda dos amigos (36,5\%) é maior do que o posicionamento negativo, ou seja, discordam que possam confiar $(19,4 \%)$ e que possam contar com eles (12,7\%). Em geral, $70,5 \%$ dos participantes estão satisfeitos $(46,9 \%)$ ou muito satisfeitos $(23,6 \%)$ com o apoio recebido. Isso tudo, considerado de modo conjunto, talvez seja um fator importante a influenciar o reconhecimento da maioria dos participantes $(77,9 \%)$ sobre estar satisfeita consigo mesma. Os insatisfeitos somam apenas $6,4 \%$, enquanto $15,6 \%$ se posicionaram de modo neutro.

Este estudo trouxe informações sobre a percepção de jovens em relação à realização e aspirações escolares e a rede de apoio social relacionadas ao contexto de ensino-aprendizagem. A análise pela Abordagem Ecológica do Desenvolvimento permite uma visão mais abrangente, tomando também a perspectiva dos outros atores sociais envolvidos nesse contexto. Estes aspectos serão objetos de análise em outras publicações.

\section{Discussão}

Os fatores de risco e de proteção podem ser identificados em todos os domínios da vida dos jovens: nos próprios indivíduos, em suas famílias, em seus pares, em suas escolas, nas comunidades e em qualquer outro nível de convivência sócioambiental. Os fatores de risco não ocorrem de forma estanque, havendo entre eles considerável transversalidade e conseqüente variabilidade de influência. Por outro lado, também é notório o acompanhamento nesses contextos de fatores específicos de proteção. Nesse sentido, há diversas dimensões dos resultados desta pesquisa que são importantes para esclarecer o papel da escola na vida desses jovens, e esses aspectos podem ser analisados em uma perspectiva sistêmica a partir da Abordagem Ecológica do Desenvolvimento e da Psicologia Positiva (Bronfenbrenner, 1996; Bronfenbrenner \& Morris, 1998; Seligman \& Csikszentmihalyi, 2000).

Segundo alguns autores (Branden, 1998; Garmezy \& Masten, 1994), a escola é um importante fator contextual de apoio do meio ambiente externo, quando promove o bom relacionamento com amigos, professores ou pessoas que assumam papel de referência segura. Além disso, a literatura (Cardenas, 2000; Sudbrack \& Dalbosco, 2005) também ressalta que a escola é um referencial estruturante em uma fase importante da formação da personalidade. A escola, segundo o paradigma da psicologia positiva, precisa funcionar como promotora de saúde e bem estar fortalecendo o "florescimento" dos jovens (Keyes \& Haidt, 2003; Seligman, 2002). Pode, portanto, se constituir como fator de proteção, característica potencial na promoção da resiliência, quando realiza ações que procurem amenizar fatores de risco, estimulando o desenvolvimento de habilidades sociais, a visão positiva de si mesmo, a cooperação, as relações afetivas, além da autoconfiança no que se refere à competência social e emocional. Isto pode ser desenvolvido pela escola a partir de ações, projetos e trabalhos de relativamente fácil execução, desde 
que haja um plano de metas organizado pelos atores escolares e motivação para cumpri-lo. Pesquisas sobre violências nas escolas (Galvão, 2003; Lopes \& Galvão, 2005) investigaram atitudes e projetos bem-sucedidos no combate às violências e na construção de uma cultura de paz. Os projetos desenvolvidos nessas escolas, identificados, particularmente pela pesquisa de Galvão (2003) eram de denominação e execução simples (bolo com coca-cola, moda e história, debate político), no entanto traziam subjacente a idéia comum de fazer com que estudantes falassem de si mesmos, de suas famílias e da sua comunidade, identificando problemas, como estes os afetavam e formas de enfrentamento. Em outras palavras, a base do sucesso de uma cultura de paz nessas escolas envolvia o desenvolvimento de uma série de projetos que visavam à construção e à afirmação de uma identidade de pertencimento, bem como uma visão crítica e politizada do mundo, compreendido em suas diferentes dimensões. Assim os estudantes, por meio de temas condutores como 'o papel da moda ao longo dos séculos', 'significados de cidadania', 'experiências artísticas' debatiam temas que refletiam desde o contexto mais amplo, até aspectos mais específicos de sua experiência subjetiva. As escolas promotoras de resiliência tinham como aspecto comum uma equipe engajada, unida e com atuação duradoura. Mudanças na direção da escola não influenciavam negativamente o desenvolvimento desses projetos. Havia entre os professores, um raro orgulho profissional (especialmente em se tratando de servidores da rede pública) derivado da consciência de um trabalho bem realizado.
Os resultados da análise do mesossistema, família e escola, nessa pesquisa enfatizaram que esses dois contextos são fundamentais como rede de apoio para os jovens. Foi possível identificar uma rede de apoio e proteção que, embora envolva a família, se constitui também nas diferentes camadas do contexto escolar. Os participantes confiam nos amigos, nos professores (embora apenas relativamente) e na estrutura escolar. Confiam, também, que estes diferentes seguimentos estão aí para ajudá-los quando necessário. A maioria gosta da escola, quer freqüentá-la, aprecia o ambiente de que desfruta cotidianamente e deseja continuar lá. No entanto os resultados sobre as relações de confiança são um tanto contraditórios. Por um lado, há respostas com posicionamento neutro ou indeciso (não concordam/nem discordam) sobre se confiam nas várias instâncias questionadas. Por outro, a maioria dos participantes está satisfeita com o apoio recebido. Nesse sentido é fundamental também ser analisado o papel dos professores, que poderiam funcionar como uma rede de apoio e proteção mais efetiva no contexto escolar, diminuindo a incidência dos fatores de risco.

Ao se analisar o modo de relação - que na perspectiva de Bronfenbrenner (1996), diz respeito a um processo que envolve as características da pessoa e do ambiente - estes resultados indicam que os jovens, se não têm uma percepção plenamente positiva dos professores, já que menos de $50 \%$ dizem que podem contar $(40,5 \%)$ ou confiar $(37,7 \%)$, também não são completamente negativos (60\% declararam gostar dos professores). Ou seja, se não confiam completamente neles como redes de apoio, também não deixam de confiar de modo explícito. Isto é paradoxal e precisa ser mais bem 
avaliado. A escola é um contexto importante como promotor de resiliência acadêmica e em especial em pesquisas sobre violências nas escolas tem apresentado papel relevante (Galvão, 2003; Lopes \& Galvão, 2005; Ribeiro \& Galvão, 2005) A ênfase no clima afetivo saudável têm sido descrito por estes autores como importante fator de proteção.

Os jovens ressaltam a importância das relações de amizade, que organizam o microssistema relacional (Bronfenbrenner, 1996; Bronfenbrenner \& Morris, 1998). O contexto da escola tem sido apontado como um ambiente favorecedor dessas relações, que pode ser um fator importante de proteção, contribuindo para o desenvolvimento da competência social e da aquisição de habilidades essenciais para o desenvolvimento afetivo e sóciocognitivo. Além disso, os processos de amizade propiciam recursos emocionais, que aumentam a capacidade para enfrentar positivamente as demandas do ambiente (Cardenas, 2000; Ladd, Kochenderfer, \& Coleman, 1996; Newcomb \& Bagwell, 1996; Price \& Ladd, 1986).

Se por um lado são encontrados no contexto da escola fatores de proteção, por outro lado, as dificuldades de aprendizagem, o fracasso e a evasão também são aparentes. Associado a isto a violência nas escolas e o uso de drogas podem também se constituir em importantes fatores de risco para a esta faixa etária. Algumas pesquisas (Galvão \& Amparo, 2005; Lopes \& Galvão, 2005; Ribeiro \& Galvão, 2005) foram unânimes em apontar a escola como um lugar de possibilidades de aprendizagem para a violência.

Segundo estudo de Maughan, Gray e Rutter (1985), o fracasso escolar persistente na adolescência e juventude traz no seu bojo o risco da desadaptação associado à evasão. Tais precursores escolares prognosticam subemprego e aumento de possibilidades de afiliação a grupos marginalizados e a exclusão social, restringindo oportunidades favoráveis ao desenvolvimento. Nesta amostra, os jovens revelam ainda boa freqüência às aulas e baixos índices de expulsão. No entanto, a reprovação é preocupante e indica a necessidade de uma revisão de procedimentos pedagógicos para uma aprendizagem mais eficiente.

Dificuldades de aprendizagem podem ser vistas como uma condição de vulnerabilidade social, pois em decorrência desse fator, as pessoas apresentam baixa auto-estima e sentimentos de inferioridade (Rutter, 1987). A vulnerabilidade de adolescentes e jovens que apresentam dificuldades de aprendizagem se reflete em desajustamento social e comportamentos anti-sociais (Spreen, 1982). Além disto, os insucessos na escola freqüentemente são acompanhados de déficits em habilidades sociais e problemas emocionais ou de comportamento. Quando essas condições persistem e são concomitantes à incidência de fatores de risco no ambiente social e familiar mais amplo, podem afetar negativamente o desenvolvimento do indivíduo em etapas subseqüentes (Santos \& Marturano, 1999).

Alguns estudos (Branden, 1998; Garmezy \& Masten, 1994) consideram que a presença de características individuais, tais como auto-estima positiva, autocontrole, autonomia, características de temperamento afetuoso e flexível; apoio afetivo na família, como coesão, estabilidade, respeito mútuo, apoio/suporte; e, apoio do meio ambiente externo, promovido por pessoas significativas, como escola, igreja, grupos de ajuda são importantes fatores de 
proteção para o desenvolvimento integral. Conseqüentemente estes aspectos contribuem para a diminuição dos riscos promovendo bom relacionamento com amigos, professores ou pessoas que assumam papel de referência segura. O senso de pertencimento juntamente com o de identidade psicossocial também tem sido identificado em outras pesquisas com jovens em situação de risco como fundamental fator de proteção (Amparo, Biasoli-Alves, \& Cárdenas, 2004; Biasoli-Alves, Amparo, Cardenas, Bisinoto, \& Santana, 2005).

Os resultados desta pesquisa enfatizam o papel da escola enquanto promotora de características positivas e as relações que jovens de nível sócio econômico baixo podem desenvolver com ela. A autoconfiança é um fator importante no desenvolvimento da auto-estima se considerado que esse aspecto também está relacionado com a capacidade de idealização e elaboração de projetos de futuro. A maior parte dos adolescentes pesquisados declara a escola importante em suas vidas e a tem como uma parte fundamental de seus projetos futuros, que incluem cursar uma universidade. Se por um lado a escola parece ter um papel importante na construção da auto-estima dos participantes, por outro, muitos dos respondentes não acreditam que realmente entrarão para a universidade. Identificam, portanto, as deficiências e falhas do sistema educacional, ressaltando principalmente a representação negativa que têm em relação aos estudantes de escolas públicas. Isto, no entanto, é minimizado pelo fato de indicarem que o sucesso escolar é dependente em certa medida de esforços exclusivamente pessoais. Portanto, afirmam que o empenho pessoal de cada um deles na aprendizagem pode minimizar os efeitos negativos de uma escola de eficiência questionável.

De modo geral, as escolas do contexto deste estudo foram avaliadas como contextos protetivos para os jovens. Os processos de proteção têm um importante papel no estabelecimento e na manutenção da auto-estima e auto-eficácia, por meio do estabelecimento de relações de apego seguras e do cumprimento de tarefas com sucesso. Criam-se, dessa forma, oportunidades para reverter os efeitos do risco e dos eventos estressores, fatos que reduzem os impactos negativos no desenvolvimento, alterando a exposição e o poder da pessoa à situação adversa (Rutter, 1987).

As escolas e seus atores (amigos, professores) podem atuar como contextos de valorização para o desenvolvimento dos jovens, enquanto seres singulares, que possam vir a exercer sua cidadania dentro de uma visão ética de mundo. Nesse sentido, a Psicologia Positiva (Keyes \& Haidt, 2003; Seligma, 2002) utilizada como pano de fundo permite ver a escola e seus atores em ação em seu contexto, assim como a rede de relações que permite o "florescimento" do jovem, valorizando sua saúde e bem estar.

\section{Conclusão}

Somente um trabalho conjunto entre a escola, a família e demais instituições responsáveis pela proteção aos direitos e ao desenvolvimento de crianças, adolescentes e jovens permitirá o pleno alcance desta meta prioritária no atual cenário brasileiro. As pessoas em desenvolvimento deixarão de representar apenas "números", para se tornarem 
verdadeiros protagonistas do desenvolvimento social, com acesso à educação, à família, ao lazer e ao atendimento de suas necessidades. Para tal, a escola compreende tanto uma completa formação como a plena escolarização. Trata-se de juntar educação formativa e educação instrucional. Juntamente com a família, a escola é uma instituição de vanguarda no processo decisivo na formação cidadã, promovendo a construção e a garantia de sujeitos plenos, capazes de exercitar seus direitos e corresponder com seus deveres à sociedade que os integra.

Dos dados emergem situações preocupantes pelo tipo de impacto que provocam. Por exemplo, o índice de estudantes que já foram reprovados ao menos uma vez (43\%) é alarmante. Reprovações geram sentimentos de fracasso que, se não forem bem trabalhados pela escola, podem levar o estudante a se distanciar dela, como indicam diversos estudos, já clássicos, sobre o assunto (Seligman \& Maier, 1967; Weiner, 1990). Outro aspecto preocupante relaciona-se aos dados, um tanto contraditórios, de que $60 \%$ dos participantes declararam gostar dos professores, mas somente $40,5 \%$ podem contar e $37,7 \%$ confiam. A escola, enquanto sistema dinâmico, para funcionar bem, demanda uma relação professor/estudante com alto grau de confiança mútua. Isto é relevante tanto para o sucesso acadêmico (Weiner, 1990) quanto para a construção de uma cultura de paz (Galvão, 2003; Lopes \& Galvão, 2005). A escola precisa construir uma cultura de confiança, para além dos vínculos emocionais entre professores e estudantes, de certa forma, traduzidos pela expressão 'gostar' .

Enfatiza-se, desta forma, o papel fundamental da escola como ponto de partida para toda e qualquer ação educativa relativa à população juvenil. Tratase do resgate dos jovens enquanto sujeitos transformadores. A escola pode realizar ações que procurem amenizar fatores de risco, implementando ações que promovam e estimulem as habilidades sociais, a visão positiva de si próprio, a cooperação, as relações afetivas, o compromisso consigo mesmo, além da autoconfiança no que se refere à competência social e emocional. Ainda, pode a escola favorecer a consciência sobre as dificuldades pessoais de cada um e encorajar uma atuação para o enfrentamento das limitações, assumindo um papel como cidadãos responsáveis. Para tanto é fundamental como fator de proteção, um clima escolar afetivo, no qual os estudantes possam contar com apoio pedagógico, baseados em parâmetros claros e consistentes, que possibilitem o desenvolvimento comprometido e prazeroso. Assim são mobilizados recursos na busca de realização pessoal e a vivência de oportunidades de participação ativa. O mesmo ocorre quando os professores têm altas expectativas em relação aos estudantes e procuram envolvê-los, com responsabilidade, nas tarefas e decisões escolares. Ao favorecer um ambiente de construção do conhecimento, propicia-se a reflexão de todos os atores deste contexto ecológico, acerca de seus comportamentos e seu projeto de vida, objetivando um viver direcionado à saúde e qualidade de vida.

O envolvimento de professores com uma atitude pedagógica que leve em conta o desenvolvimento de uma atitude responsável para com a aprendizagem faz emergir estudantes mais conscientes de si e do mundo, mais capazes de resistir às pressões do grupo em relação a temas e situações que não são do seu interesse. Talvez o 
desenvolvimento relacional tenha de caminhar neste sentido para proporcionar uma relação de confiança mais extensiva e profunda. A apropriação e a disseminação de informações favorecerão estratégias de comportamento saudáveis, tais como evitar o uso de drogas, e os fatores de risco na sua incidência, tanto micro quanto mesossistêmico. É importante considerar que a relativa fragilidade das relações estudantes-professores indica a necessidade de investimento em políticas governamentais que visem à formação dos profissionais e ao preparo destes para lidarem com situações adversas, bem como para potencionalizar a escola como lugar de proteção, minimizando as vulnerabilidades.

Este estudo possibitou focalizar em aspectos mais específicos relacionados à escola e deixa várias questões para futuras investigações. Por exemplo, seria interessante analisar a relação entre a percepção dos estudantes sobre o papel da escola e a repetência, desta com a auto-eficácia, da autoeficácia com uso de drogas e ações que geram conflito com a lei. Além disso, é possível também separar grupos por conta de características específicas como estrutura familiar, índice de escolaridade e renda dos pais, entre outros. A base de dados desta pesquisa é bastante rica. Este o primeiro de uma série de trabalhos que servirá para melhorar o conhecimento sobre a população estudada, permitindo sugerir políticas educacionais mais eficientes.

\section{Referências}

Amparo, D. M., Biasoli-Alves, P., \& Cárdenas, C. J. (2004). Pertencimento e identidade em adolescentes em situação de risco de Brasília. Revista Brasileira de Crescimento e Desenvolvimento Humano, 14(1), 1-13.

Biasoli-Alves, P., Amparo, D. M., Cárdenas, C. J., Bisinoto, C., \& Santana, P. (2005). Adolescência e violência: habilidades, competência e resoluções resilientes para a promoção da paz. Em L. F. Costa \& T. M. C. Almeida (Eds.), Violência no cotidiano (pp. 141166). Brasília: Universa/Líber.

Branden, N. (1998). Auto-estima: como aprender a gostar de si mesmo. São Paulo: Saraiva.

Bronfenbrenner, U. (1986). Ecology of the family as a context for human development: research perspectives. Developmental Psychology, 22, 723-742.

Bronfenbrenner, U. (1989). Ecological systems theory. Em R. Vasta (Ed.), Annals of Child Development: Vol. 6 (pp. 187-251). Greenwich, CT: JAI.

Bronfenbrenner, U. (1996). A ecologia do desenvolvimento humano: experimentos naturais $e$ planejados. Porto Alegre: Artes Médicas. (Original publicado em 1979).

Bronfenbrenner, U. (2005). Making human beings human: Bioecological perspectives on human development. London: Sage.

Bronfenbrenner, U., \& Morris, P. (1998). The ecology of developmental processes. Em W. Damon (Ed.), Handbook of child psychology (Vol. 1, pp. 993-1027) New York, NY: John Wiley \& Sons.

Cardenas, J. C. (2000). Adolescendo: Um estudo sobre a constituição da identidade do adolescente no âmbito da 
escola. Tese de Doutorado não publicada, Instituto de Psicologia, Universidade de Brasília, Brasília.

Dell'Aglio, D. D., Koller, S., \& Yunes, M. A. (2006). Resiliência e psicologia positiva: interfaces do risco à proteção. São Paulo: Casa do Psicólogo.

Engle, P. L., Castle, S., \& Menon, P. (1996). Child development: Vulnerability and resilience. Social Science Medicine, 43(5), 621-635.

Galvão, A. C. T. (2003). As escolas inovadoras: Distrito Federal. Em M. Abramovay (Org.), Escolas inovadoras: experiências bem-sucedidas em escolas públicas (pp. 159-172). Brasília: Unesco.

Galvão, A. \& Amparo, D. (2005). Violência nas escolas e ansiedade do professor: um estudo de caso. Em Anais do II Congresso Ibero-Americano de Violência nas Escolas (pp. 1-15). Belém: UNESCO.

Garmezy, N., \& Masten, A. (1994). Chronic adversities. Em M. Rutter, E. Taylor \& L. Herson (Eds.), Child and adolescent psychiatry (pp. 191-207). Oxford: Blackwell Scientific.

Instituto Brasileiro de Geografia e Estatística (2005). Pesquisa nacional por amostra de domicílios: síntese dos indicadores de 2004. Rio de Janeiro, Brasil: IBGE Departamento de emprego e rendimento.

Keyes, C. L. M., \& Haidt, J. (Eds.). (2003). Flourishing: Positive psychology and the life well lived. Washington DC: American Psychological Association.

Koller, S., Cerqueira-Santos, E., Morais, N. A., \& Ribeiro, J. (2005). Relatório sobre a juventude brasileira. Washington, DC: World Bank.

Ladd, G. W., Kochenderfer, B. J., \& Coleman, C. C. (1996). Friendship quality as a predictor of young children's early school adjustment. Child Development,
$6,1103-1118$.

Leite, S. A. da S., \& Tagliaferro, A. R. (2005). A afetividade na sala de aula: um professor inesquecível. Psicologia Escolar e Educacional, 9(2), 247-260.

Lisboa, C., \& Koller, S. H. (2004). Interações na escola e processos de aprendizagem:fatores de risco e proteção. Em E. Boruchovitch \& J. A. Bzuneck (Eds.), Aprendizagem: Processos psicológicos e o contexto social na escola (pp. 201-224). Petrópolis: Vozes.

Lopes, R. B., \& Galvão, A. C. T. (2005) Violência nas escolas fatores externos e internos. Educare, 1(1), 152169.

Maughan, B., Gray, G., \& Rutter M. (1985). Reading retardation and social behaviour: A follow-up into employment. Journal of Child Psychology and Psychiatry, 26, 741-758.

Morais, N. A., \& Koller, S. H. (2004). Abordagem ecológica do desenvolvimento humano, psicologia positiva e resiliência: A ênfase na saúde. Em S. Koller (Ed.), Ecologia do desenvolvimento humano: Pesquisa e intervenção no Brasil (pp. 91-107). São Paulo: Casa do Psicólogo.

Newcomb, A. F., \& Bagwell, C. L. (1996). The developmental significance of children's friendship relations. Em W. M. Bukowski, A. F. Newcomb \& W. W. Hartup (Eds.), The company they keep: Friendship in childhood and adolescence (pp. 228-321). New York: Cambridge University Press.

Organização dos Estados Ibero-Americanos para Educação, Ciência e Cultura (2006). Relatório de Desenvolvimento Juvenil 2006. Recuperado: $26 \mathrm{dez}$. 2007. Disponível: http://www.oei.org.br.

Pesce, R., Assis, S., Santos, N., \& Oliveira, N. (2005). Risco e proteção: em busca de um equilíbrio promotor de 
resiliência. Psicologia: Teoria e Pesquisa, 20(2), 135143.

Pinheiro, D. P. N. (2004). A resiliência em discussão. Psicologia em Estudo, 9(1), 67-75.

Price, J. M., \& Ladd, G. W. (1986). Assessment of children's friendship: Implications for social competence and social adjustment. Em R. J. Prinz (Ed.), Advances in behavioral assessment of children and families (Vol. 2, pp.121-149). Greenwich, CT: JAI Press.

Rutter, M. (1987). Psychosocial resilience and protective mechanisms. American Orthopsychiatric Association, 57(3), 316-331.

Rutter, M. (1993). Resilience: Some conceptual considerations. Journal of Adolescent Health, 14, 626631.

Ribeiro, R. C., \& Galvão, A. C. T. (2005). Violência escolar e suas significações para estudantes. Em Anais do II Congresso Ibero-Americano de Violência nas Escolas (pp. 15-30). Belém: UNESCO.

Santos, L. C., \& Marturano, E. M. (1999). Crianças com dificuldades de aprendizagem um estudo de seguimento. Psicologia Reflexão e Crítica, 12(2), 377-394.

Seligman, M. E. P. (2002). Authentic Happiness: Using the New Positive Psychology to Realize Your Potential for Lasting Fulfillment. New York: Free Press/Simon and Schuster.

Seligman, M. E. P., \& Csikszentmihalyi, M. (2000). Positive psychology: An introduction. American Psychologist, 55(1), 5-14.
Sposito, M. P. (2000). Estado do conhecimento. juventude e educação. São Paulo: Ação Educativa.

Sposito, M. P., \& Corrochano, M. C. (2005). A face oculta da transferência de renda para jovens no Brasil. Tempo Social, 17(2), 141-172.

Sudbrack, M. F. O., \& Dalbosco, C. (2005). Escola como contexto de proteção: refletindo sobre o papel do educador na prevenção do uso indevido de drogas. Em II Simpósio Internacional do Adolescente, São Paulo. Recuperado: $28 \quad$ set 2006. Disponível:http://www.proceedings.scielo.br/scielo.php? script=sci_arttext\&pid=MSC0000000082005000200082 $\& \operatorname{lng}=\mathrm{en} \& \mathrm{nrm}=\mathrm{abn}$.

Spreen, O. (1982). Adult outcome of reading disorders. Em R. N. Malatesta \& P. G. A. Aaron (Eds.), Reading disorders: Varieties and treatments (pp. 473-492). New York Academic Press.

Waiselfisz, J. J. (2006). O mapa da violência. Recuperado: $26 \mathrm{dez} 2006 . \quad$ Disponível: http://www.dominiopublico.gov.br/download/texto/ue00 0080.pdf.

Weiner, B. (1990). History of motivational research in education. Journal of Educational Psychology, 82, pp616-622.

Yunes, M. A. M. (2003). Psicologia positiva e resiliência: o foco no indivíduo e na família. Psicologia em Estudo, 8, 75-84.

Zimmerman, M. A., \& Arunkumar, R. (1994). Resiliency research: Implications for schools and policy. Social Policy Report, 8, 1-18. 
Recebido em: 17/03/2007

Revisado em: 28/04/2008

Aprovado em: 05/06/2008

Sobre os autores:

Deise Matos do Amparo (deise@ucb.br) - Professora do Programa de Pós-graduação em Psicologia - Universidade Católica de Brasília

Afonso Celso Tanus Galvão (agalvao@ pos.ucb.br) - Professor dos Programas de Pós-graduação em Educação e em Psicologia - Universidade Católica de Brasília

Carmen Cardenas (ccardena@pos.ucb.br) - Professora dos Programas de Pós-graduação em Gerontologia e em Psicologia - Universidade Católica de Brasília

Sílvia Helena Koller (skoller@uol.com.br) - Professora do Programa de Pós-graduação em Psicologia - Universidade Federal do Rio Grande do Sul UFRG

\section{Endereço para correspondência}

Deise Matos do Amparo

Universidade Católica de Brasília

Pró Reitoria de Pós-Graduação e Pesquisa

Campus II

SGAN - 916, Módulo B, W3 Norte

Brasília - DF

CEP: 70790-160

Mestrado em Psicologia

E-mail: deise@ucb.br 